\title{
Movimiento e imperialismo Inca en los valles de Arica (Andes $18^{\circ} \mathrm{S}$ )
}

\author{
Pablo Mendez-Quiros Aranda (i) y Thibault Saintenoy (D)
}

\begin{abstract}
Haciendo eco de las crónicas coloniales sobre el sistema vial imperial andino, la mayoría de las investigaciones sobre caminos incaicos se han centrado en su planificación y tecnología monumental como las principales características de esta infraestructura prehispánica tardía. Mediante un estudio regional en los valles de Arica $\left(18^{\circ} \mathrm{S}\right)$, abordamos, en este trabajo, una investigación del Qhapaq Ñan (sistema vial incaico) desde una perspectiva de redes. Analizamos un palimpsesto de $13.000 \mathrm{~km}$ de vías, producido por la acumulación de sistemas viales de distintos períodos cronológicos. Este es relacionado con el patrón de asentamiento prehispánico tardío para modelizar los flujos de movimiento durante los siglos quince y dieciséis: mediante análisis espaciales, delineamos las estructuras más probables de las redes viales local e imperial. Finalmente, consideramos medidas de centralidades y acumulación de flujo para discutir la hipótesis del control del movimiento como estrategia imperial. Los resultados muestran que la hegemonía incaica se pudo relacionar con el control espacial de los flujos de las interacciones, y también que el enfoque de red aplicado a los palimpsestos viales reviste gran potencial para la arqueología del movimiento en regiones desérticas y montañosas.
\end{abstract}

Palabras clave: territorio, patrón de asentamiento, redes viales, imperialismo, Qhapaq Nan, Inca, Andes

Echoing colonial chronicles about the imperial Andean road system, most research on Inca roads has focused on monumental technology and planning as the main characteristics of this late prehispanic infrastructure. Through a regional case study of the Arica valleys $\left(18^{\circ} \mathrm{S}\right)$, we show that the Qhapaq Nan (Inca road system) research may also be understood by considering network dynamics, and not necessarily centered on an exclusive monumental road. We analyze a palimpsest composed of around 13,000 km of roads and paths (extending through deserts, valleys, and mountains) produced by the accumulation through time of road systems of distinct chronological periods. Here, we connect this palimpsest to the late prehispanic settlement pattern to model the flows of movement in the region during the fifteenth and sixteenth centuries. Spatial analyses allow us to identify the most likely structure of local and imperial networks. Finally, we use measurements of centralities and flow accumulation to address the hypothesis that the control of movement was an imperial strategy. The results show that Inca hegemony may have been related to the spatial control of the interaction flows within the region, and also that the palimpsestbased network approach has great potential for the archaeological study of roads in desert and mountain regions.

Keywords: territory, settlement pattern, road networks, imperialism, Qhapaq Ñan, Inca, Andes

$\mathrm{V}$ isto desde el cielo, el paisaje desértico de los valles de Arica está marcado por muchas líneas entrecruzadas a través de las pampas, valles y sierras. La gran mayoría de estas líneas no figuran en la cartografía, porque son caminos abandonados desde el éxodo rural ocurrido durante el siglo veinte, cuando se generalizó la movilidad motorizada. Tomadas en conjunto, estas líneas se asemejan a un palimpsesto, es decir un complejo heterogéneo de caminos formado por la acumulación de redes viales correspondientes a distintas coyunturas históricas.

Pablo Mendez-Quiros Aranda — (mendez.quiros@ gmail.com) Universitat Autònoma de Barcelona, Departament de Prehistoria, 08193 Bellaterra (Barcelona), España

Thibault Saintenoy (tsaintenoy@gmail.com, autor de contacto) — Instituto de Ciencias del Patrimonio, Consejo Superior de Investigaciones Científicas, Avenida de Vigo s/n, 15705, Santiago de Compostela, España; Laboratoire AiHP-GEODE Caraïbe (EA929), Université des Antilles, 97233, Schoelcher, France

Latin American Antiquity 32(2), 2021, pp. 331-349

Copyright (C) The Author(s), 2021. Published by Cambridge University Press on behalf of the Society for American Archaeology. This is an Open Access article, distributed under the terms of the Creative Commons Attribution licence (http://creativecommons.org/licenses/by/4.0/), which permits unrestricted re-use, distribution, and reproduction in any medium, provided the original work is properly cited. 
Este artículo expone el resultado del registro del palimpsesto vial de la región de Arica y analiza su relación con el patrón de asentamiento de la época prehispánica tardía (siglos quince y dieciséis). Desde un punto de vista teórico y metodológico, se evalúa el potencial de análisis de las infraestructuras y huellas del movimiento para explicar la organización de los antiguos sistemas de asentamiento y movilidad. Desde un punto de vista histórico, el análisis del antiguo sistema vial es especialmente pertinente para el estudio del poblamiento prehispánico tardío cuyo modelo territorial, caracterizado por formaciones archipelágicas, otorgaba un papel fundamental a la movilidad.

Se analizan los sistemas de asentamiento y movilidad prehispánicos tardíos en los valles de Arica, en el contexto del imperialismo incaico. Específicamente, la investigación busca evaluar un hipotético control imperial de la movilidad: efectivamente, ante un poblamiento segmentado entre nichos con recursos diferenciados y complementarios, la estructuración de la movilidad de personas, bienes e ideas podría haber constituido una estrategia de hegemonía imperial.

Después de una síntesis de datos arqueológicos y etnohistóricos sobre la organización socioterritorial del poblamiento prehispánico tardío en los valles de Arica, se presenta primero la metodología de registro y evaluación cronológica del palimpsesto vial. En una segunda parte, se exponen los resultados de análisis de patrones de asentamiento y flujos de movilidad asociados, para finalmente discutirse los alcances teóricos y metodológicos de nuestra aproximación para renovar los estudios arqueológicos del sistema vial incaico.

\section{Antecedentes sobre los valles de Arica durante la época prehispánica tardía}

\section{Organización socioterritorial}

Durante la época prehispánica tardía, los valles de Arica formaban parte de la partición territorial conocida como Colesuyu, la que agrupaba a los valles occidentales entre Moquegua y Arica (Rostworowski 1986). La información etnohistórica, derivada de crónicas y censos coloniales, evidencia un poblamiento multiétnico con alto grado de imbricación socioterritorial entre los distintos grupos humanos que los habitaban. Esta situación se relaciona, en gran medida, con la intensidad de las interacciones verticales entre tierras bajas y altas, en el contexto de la ecología multizonal andina (Masuda et al. 1985). Las visitas coloniales evidencian distintas formaciones socioterritoriales reticulares extendidas entre el Altiplano y el Pacífico, correspondientes al clásico modelo territorial del archipiélago andino (Murra 1975).

En los valles de Arica, la presencia de colectivos carangas y lupacas, originarios del Altiplano, está documentada en archivos de los siglos dieciséis y diecisiete (Durston e Hidalgo 1997). Ellos coexistieron con colectivos coles y camanchacas, agricultores y pescadores de raigambre más local (Choque 2009). La diversidad cultural del registro arqueológico en los sitios correspondientes a asentamientos y cementerios de la época prehispánica tardía (siglos trece a dieciséis) se relaciona sin duda con este poblamiento multiétnico (Hidalgo y Focacci 1986; Horta 2015). Por ejemplo, estos sitios combinan sistemáticamente tipos de cerámica diversos, tanto por su decoración como por su tecnología (Flewett et al. 2016). Si bien la distinción de colectivos étnicos a partir del registro arqueológico es una tarea compleja, queda claro que coexistieron redes de asentamientos dispersas y discontinuas, asociadas a estos colectivos sociales, en distintos nichos ecológicos, pisos altitudinales y valles para aprovechar el potencial de las distintas aguas (Álvarez 1991).

\section{Estudios de patrones de asentamiento}

Desde los trabajos pioneros de Uhle y Bird, la arqueología de los valles de Arica se ha centrado en la excavación de sitios estratificados, cementerios y conchales, con el objetivo fundamental de elaborar secuencias culturales (Munizaga 1957). El primer mapa arqueológico de la región fue elaborado por Dauelsberg (1959a, 1959b, 1960) en la década de 1950, para determinar el alcance de la ocupación prehispánica más allá de los alrededores de la ciudad de Arica, donde se habían concentrado las investigaciones hasta ese entonces.

El interés por las dinámicas del poblamiento regional se desarrolló a partir de los años setenta. Progresivamente, durante cuatro décadas, se realizaron reconocimientos arqueológicos en distintas zonas, donde la identificación de conjuntos de sitios permitió vislumbrar procesos históricos 
locales y discutir sus implicancias para la historia regional. La cuenca del valle de Camarones fue explorada tempranamente durante los años setenta y ochenta (Muñoz y Santos 1998; Niemeyer y Schiappacasse 1981; Niemeyer et al. 1971). Las tierras altas de las cuencas de Lluta, Azapa y Vitor han sido objeto de recurrentes reconocimientos durante las décadas de 1980, 1990 y 2000 (Dauelsberg 1983; Muñoz y Chacama 2006). A finales de los noventa, un proyecto de prospección intensiva generó un extenso mapa arqueológico del valle de Lluta (Romero et al. 2000).

Hoy en día, después de una década de creciente accesibilidad a imágenes aéreas de alta resolución y sistemas de geoposicionamiento, en el marco de proyectos de gestión patrimonial y de ciencia básica, se dispone de un mapa arqueológico detallado para la región de Arica y Parinacota (Ajata 2015; Oyaneder y Alday 2016; Romero et al. 2008; Saintenoy et al. 2017). Pero a pesar de esta relativa abundancia de información en publicaciones, la creación de una base de datos que compile el conjunto de sitios identificados es una tarea aún pendiente.

La gran mayoría de investigaciones sobre patrones de asentamiento en los valles de Arica se han interesado por la época prehispánica tardía. Ello se explica por la excelente conservación de una importante cantidad de asentamientos de esta época, pero también por la influencia académica de la etnohistoria andina sobre los modelos territoriales premodernos, referentes al imperialismo incaico y al reordenamiento colonial (Hidalgo 2004).

\section{Imperialismo incaico}

La influencia imperial en los valles de Arica está materializada principalmente por la arquitectura, la cerámica y los textiles. Aunque no se han registrado casos de mampostería incaica emblemática, la presencia de recintos de planta rectangular (especialmente los de forma alargada y distribuidos alrededor de un patio), de mausoleos de piedra e incluso ciertos recintos circulares (de factura distinta a la arquitectura doméstica vernácula), evidencian la influencia incaica. Los tipos cerámicos emparentados a la cultura material incaica incluyen estilos con decoración polícroma, aunque predominan los estilos imperiales asociados a la tradición negro sobre rojo (especialmente el estilo Saxamar, pero también las pastas finas de superficie bruñida, decorada con motivos geométricos incaicos pintados con líneas negras finas). Aunque se han recuperado notables túnicas uncus y quipus, los textiles son un indicador parcial para la aproximación regional porque su registro se limita en gran medida a contextos funerarios (excavados) en tierras bajas, a diferencia de la arquitectura y cerámica que se registra potencialmente (en superficie) en toda la región, independientemente de las condiciones de conservación.

El imperialismo incaico ha sido comúnmente interpretado en función del clásico modelo de control directo/indirecto, territorial/hegemónico (D’Altroy 1992). A partir de la aparente concentración de arquitectura con influencia incaica en las tierras altas, se ha postulado el control territorial de dicha región, diferenciado de una influencia hegemónica en los valles bajos y costa (Covey 2000; Santoro et al. 2010). De hecho, una hipótesis recurrente relaciona la difusión de la influencia imperial con la presencia de grupos altiplánicos a través de los valles hacia el litoral (Llagostera 1976). En los valles bajos, se evidenció que el imperialismo incaico tuvo por efecto la concentración de poblaciones y la reorganización de algunos poblados (Mendez-Quiros y SilvaPinto 2015; Santoro et al. 2003), además de una importante penetración de la cultura material incaica en los contextos funerarios locales (Horta 2015). Estudios recientes han destacado el interés imperial por los nichos de producción maicera, el cual implicó la implantación de arquitectura incaica en poblados locales, el control de huacas, la instalación de colonias mitimaes y el desarrollo de infraestructuras (agrohidráulicas, logísticas y viales), como se ha planteado para la cuenca alta de Azapa (Saintenoy et al. 2019a, 2019b).

\section{Imperialismo y movimiento}

Mientras que la extensión y tecnología del sistema vial son a menudo presentadas como una metáfora corporal del territorio imperial (su columna vertebral), se resalta también comúnmente la supuesta monumentalidad empedrada del Qhapaq Nan como expresión material del ordenamiento territorial, del poder político y del control económico de la élite incaica sobre los Andes (Chacaltana et al. 
2017). Siguiendo esta idea de planificación imperial, las investigaciones históricas se interesaron tempranamente por evaluar la extensión de la red vial imperial en los Andes (Raimondi 1966 [1876]; Strube-Erdmann 1963), mientras que las investigaciones arqueológicas buscaron documentar la diversidad de soluciones tecnológicas implementadas para su acondicionamiento en escenarios biogeográficos y contextos sociopolíticos diversos (Hyslop 1991; Von Hagen 1955).

En los valles de Arica, las investigaciones han identificado un sistema vial incaico compuesto por dos ejes paralelos. El más conocido recorre las tierras altas, en torno a los $3.000 \mathrm{~m} \mathrm{snm}$, conectando las principales localidades de la sierra, siendo propuesto como un eje vertebrador para los intereses incaicos en este piso (Muñoz 2018; Santoro 1983). El segundo recorre la costa y los valles bajos, del cual no se conservarían vestigios materiales por coincidir a grosso modo con la Carretera panamericana (Muñoz y Briones 1996; Niemeyer y Schiappacasse 1998). Estos ejes fueron inferidos, en gran medida, a partir de la distribución espacial de los principales asentamientos incaicos, con referencias escasas y puntuales a tramos concretos, con excepción de los $12 \mathrm{~km}$ de camino incorporados a la lista Unesco. Este último es el único que conserva una calzada empedrada, aparte de las entradas a tres pueblos de origen colonial.

El registro empírico de caminos, tanto en terreno como a partir de imágenes aéreas, se ha incrementado los últimos años. En este contexto, el registro sistemático por fotointerpretación de los caminos visibles sobre imágenes satelitales produjo una innovación significativa para el estudio a la vez sistemático y extensivo del sistema vial incaico. Esta aproximación se diferencia de los trabajos anteriores enfocados en identificar un camino incaico específico, concebido como un itinerario exclusivo con arquitectura vial monumental.

La aproximación que fundamentó nuestro registro de todos las vías visibles se basa en una aprehensión palimpséstica de los conjuntos de caminos. Efectivamente, entendemos que el proceso de formación del registro arqueológico del palimpsesto vial es de tipo "acumulativo" (Bailey 2007): es decir, un proceso de larga duración donde las infraestructuras e improntas del movimiento relativas a distintas coyunturas históricas se acumulan con las reconfiguraciones de las redes viales, las cuales generalmente implican el trazado de nuevos caminos y la reutilización de antiguos, sin eliminación de las vías en desuso. De esta manera, la conservación de la traza de estas últimas siempre predispone a una eventual reutilización en posteriores evoluciones morfológicas de la red vial, en función de los cambios coyunturales de las prácticas de movilidad.

Debido a su heterogeneidad diacrónica, el carácter palimpséstico del registro de caminos plantea obviamente ciertos problemas de diagnóstico cronológico (Nuninger et al. 2020). Sin embargo, permite desarrollar modelizaciones de redes a partir de un registro empírico abundante y de gran integridad, ya que los valles de Arica, como otras regiones desérticas con baja ocupación humana, ofrecen condiciones óptimas para la conservación de caminos durante siglos después de su último uso (Nielsen 2017). Además, este tipo de registro permite abordar la problemática de las interacciones durante el Horizonte Tardío en términos de redes y, de esta manera, llevar la investigación del Qhapaq Ñan más allá del paradigma del "caminomonumento" (Verdier y Robert 2009).

Entender la organización territorial del Tawantinsuyu a partir de las propiedades reticulares de su sistema vial no es una propuesta nueva. Jenkins (2001) realizó un análisis topológico de la distribución de los centros imperiales a partir del mapa de la red vial incaica propuesta por Hyslop (1984), destacando la centralidad de ciertos centros mayores relacionados con el circuito económico de subsistencia. Para el desierto de Atacama, Zori y Brant (2017) desarrollaron un caso de estudio del control imperial de las interacciones socioespaciales entre los asentamientos incaicos, evidenciando la relación entre centralidad topológica y grado de interacción regional (evidenciada a través de la diversidad de estilos de cerámica). Finalmente, en otro estudio reciente, Wernke y colaboradores (2017) evaluaron el potencial de los principales centros incaicos para controlar flujos de movimiento de personas, bienes e ideas, a través de una vasta región en el sur del Perú, mediante la 
combinación de datos geográficos (modelo digital de elevación) y arqueológicos (registro de tramos de camino) empíricos, para simular flujos entre sitios, concluyendo a una distribución estratégica de los centros administrativos "para controlar y vigilar el tránsito a lo largo de grandes distancias a través del Tawantinsuyu".

En el presente estudio, se busca ahondar en el análisis topológico del sistema vial incaico, a partir de un caso de estudio en los valles de Arica, para explorar la potencial relación de su estructuración espacial con el dominio imperial. Asimismo, se exploran las propiedades reticulares del sistema vial, a partir de una modelización basada en el registro empírico del patrón de asentamiento prehispánico tardío y del conjunto de caminos que dejaron huellas sobre las pampas, valles y sierras de la región.

\section{Datos y metodología}

\section{Escenario biogeográfico}

Los valles de Arica se ubican en los Andes Centrosur $\left(18^{\circ} \mathrm{S}\right)$, siendo parte de la subárea de los Valles Occidentales, correspondiente al conjunto de ríos y quebradas que drenan desde los Andes hacia el Pacífico, entre Arequipa y Arica (Lumbreras 1981). Nuestra área de estudio incluye los valles de Lluta, Azapa, Vitor, Camarones y Tana. Se trata de una región desértica donde el clima varía según pisos altitudinales y donde la feracidad y poblamiento de los valles contrasta con la extrema aridez y desolación de las pampas interfluviales. Las precipitaciones se concentran durante dos o tres meses estivales y aumentan con la altitud; se originan en el Altiplano y son prácticamente nulas debajo de los $2.000 \mathrm{~m}$ snm. La intensidad de las precipitaciones ha constituido un factor fundamental relacionado con la dinámica de poblamiento. Los anillos de crecimiento de Polylepis, que constituyen el indicador de mayor resolución sobre la historia de las precipitaciones durante el último milenio, evidencian una fase húmeda asociada al desarrollo imperial incaico en el transcurso del siglo quince (Morales et al. 2012).

Como en todos los Andes, la gradiente altitudinal define pisos ecológicos. La franja litoral se caracteriza por abundantes recursos marinos y humedales en las desembocaduras. En el piso de valles bajos, entre 200 y $1.000 \mathrm{~m}$ snm aproximadamente, la agricultura de riego se practica en los fondos del valle, aprovechando las vertientes y el agua de río que drena desde las tierras altas. El piso entre 1.000 y $2.000 \mathrm{~m}$ snm aproximadamente es el más árido, al no recibir el influjo de la humedad costera y encontrarse bajo la cota de lluvias estivales. Denominado chaupiyunga en los valles de Lluta y Azapa, éste coincide con el encajonamiento de los valles causado por el alzamiento del macizo andino. La disponibilidad de agua hace del chaupiyunga un nicho agrícola privilegiado, aunque de poca extensión. Sobre los $2.000 \mathrm{~m} \mathrm{snm}$, el piso de sierra presenta un relieve rugoso formado por conjuntos de quebradas donde las lluvias estivales forman una cubierta de matorrales, pastizales e incluso bosques (Polylepis), donde la relativa abundancia de recursos hídricos ha favorecido al acondicionamiento de espacios de cultivo aterrazados. La naciente de estas cuencas se sitúa en el altiplano, encima de los $4.000 \mathrm{~m}$ snm, con la excepción de Azapa cuya geomorfología forma una cuenca alta precordillerana.

En este trabajo, la caracterización fisiográfica se basa en el modelo digital de elevación Shuttle Radar Topographic Mission (SRTM; versión 4), con una resolución de $90 \mathrm{~m}$.

\section{Sitios arqueológicos}

Se generó una base de datos de 160 sitios con ocupación prehispánica tardía, mediante la compilación de datos seleccionados en publicaciones académicas, bases de datos de gestión patrimonial e informes técnicos. Todos cuentan con una geolocalización y un diagnóstico cronológico basado en fechado(s) absoluto(s) y/o cultura material. Lamentablemente, no se dispone de datos sistemáticos de tamaños que permitan una clasificación de este orden. Se seleccionaron los asentamientos habitacionales y cementerios, por constituir los polos de presencia humana más estables y cronológicamente mejor documentados. Los cementerios (aislados) fueron incorporados en su calidad de indicador de ocupación humana estable. También fueron incluidos cuatro tambos, los cuales son importantes nodos del sistema de asentamiento y movilidad. Para evitar una sobrerrepresentación de ciertas localidades en el análisis espacial, los 
asentamientos muy próximos, así como los asentamientos asociados a cementerios, fueron fusionados en una sola entidad en la base de datos de sitios, la que se redujo a 129 entidades (Tabla Suplementaria 1).

En ausencia de evidencias estratigráficas con fechados absolutos, la distinción entre ocupaciones del período Intermedio Tardío (PIT; siglos doce a catorce) y del Horizonte Tardío (HT; siglos quince y dieciséis) resulta a menudo problemática. En efecto, el HT se diagnóstica generalmente por la presencia de cultura material emparentada al horizonte estilístico imperial, la cual se presenta de manera intrusiva en sitios donde predominan los estilo(s) local(es). No se registra ningún sitio donde la arquitectura de influencia incaica no esté asociada a componentes arquitectónicos de tradición local. La evidencia de abandono de asentamientos PIT antes del HT es muy acotada, de tal manera que la distinción suele resumirse en una dicotomía local/ imperial, relativa al grado de integración de los asentamientos locales a la esfera geopolítica imperial.

Para el análisis del imperialismo incaico, se distinguen tres tipos de asentamiento, todos con un componente local predominante: los asentamientos sin cultura material incaica $(N=67)$; los asentamientos con cerámica incaica $(N=62)$, evidenciando su participación en la red de interacción imperial; y entre estos últimos se distinguieron aquellos con arquitectura incaica $(N=15)$ cuya presencia materializa cierto control territorial.

\section{Redes viales}

Registro del palimpsesto vial. Este estudio se basa en el registro empírico de un palimpsesto vial compuesto por $13.311 \mathrm{~km}$ de vías acumuladas (Figura 1). Se realizó mediante la fotointerpretación de imágenes satelitales, de resolución submétrica, disponibles en el globo virtual Google Earth. La estructura lineal y el contraste de textura respecto al suelo constituyeron los criterios básicos de identificación de los caminos. Dada la imprecisión y variabilidad de georeferenciación y ortorectificación de las imágenes satelitales en Google Earth, la precisión de los trazados mediante polilíneas tiene un margen de error aproximado de $10 \mathrm{~m}$ en torno a la impronta de camino en la imagen.
La cartografía histórica fue consultada para su contrastación con las imágenes satelitales e incluso como fuente de registro de caminos en zonas con mala visibilidad en imágenes satelitales o afectadas por alteraciones recientes, especialmente relacionadas con la construcción de carreteras. Asimismo, los mapas de la Comisión Nacional de Limites de Chile, elaborados a principios del siglo veinte, resultaron de especial interés para completar el registro de los espacios urbanizados e industrializados litorales, además de los fondos de valle con intenso acondicionamiento agrícola.

Para los análisis de redes se realizó una normalización topológica del palimpsesto vial. Se individualizó cada tramo en función de los cruces de polilíneas, y se conectaron los tramos discontinuos por cursos hídricos. Los sitios arqueológicos desconectados fueron conectados mediante la proyección del camino más próximo. Finalmente, se simplificó el sistema vial en las áreas antropizadas y de alta densidad de ocupación actual (de carácter urbano, agrícola e industrial), como los fondos de valle, donde se representó una única línea longitudinal arbitrariamente conectada a los caminos de las laderas.

El catastro geoespacial de caminos normalizados compila 14.062 entidades lineales, constituyendo estos tramos la unidad mínima de análisis topológico. Cualquier itinerario entre sitios se compone entonces por una serie de tramos interconectados. Asimismo, un tramo puede integrar distintos itinerarios, y la cuantificación de esta acumulación de itinerarios por un determinado tramo constituye un valor de flujo.

La Figura 2 da cuenta de la distribución del palimpsesto vial por cuenca y piso altitudinal. Se registró en las cuencas de Lluta, Azapa, Vitor y Camarones una cantidad comparable de caminos, con una distribución análoga entre pisos altitudinales, observándose una tendencia al aumento de caminos subiendo en altura. La escasez de caminos en la cuenca de Escritos se explica por una ocupación humana casi nula, sumada al severo impacto producido por el Ferrocarril Arica-La Paz, mientras que la gran cantidad registrada en la cuenca de Tana, entre los 1.000 y $2.000 \mathrm{~m}$ snm, es consecuencia de la intensa explotación industrial salitrera (siglos diecinueve y veinte). La densidad de caminos, 

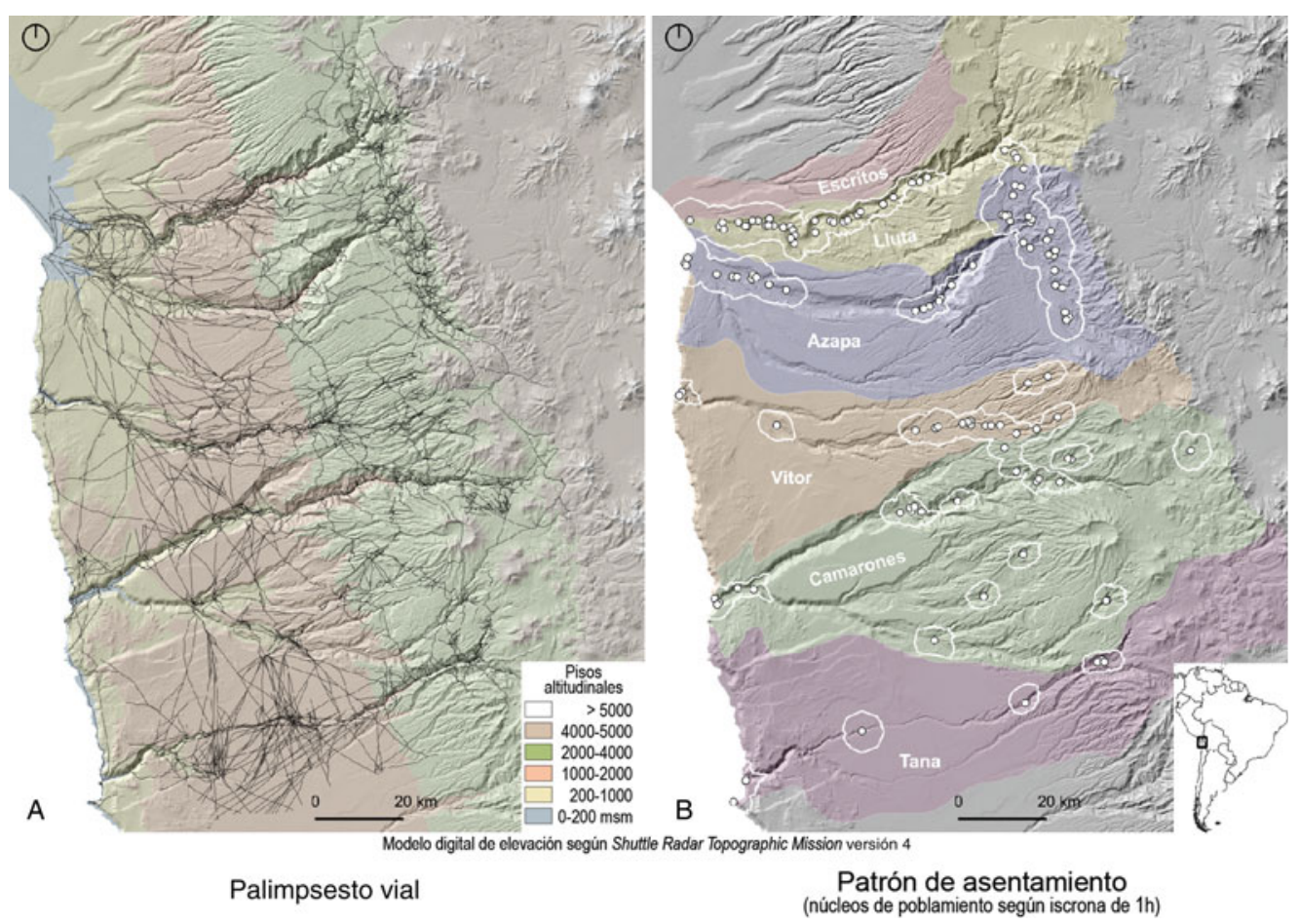

Figura 1. Configuración espacial de elementos arqueológicos analizados en los Valles Occidentales: (A) distribución del palimpsesto vial en relación a pisos altitudinales, (B) núcleos de poblamiento y asentamientos prehispánicos tardíos en los valles de Arica en relación a cuencas hidrográficas. (Color en la versión electrónica)

por su parte, es equivalente en las distintas cuencas, con ciertas diferencias entre pisos y una alta densidad en el litoral.

Modelización cronológica de la red vial prehispánica. Desde nuestra aproximación palimpséstica, entendemos que los 14.062 tramos de caminos son resultado de la superposición de distintos sistemas viales relativos a procesos históricos diacrónicos. Dos modelizaciones fueron desarrolladas para evaluar la probabilidad de uso de los tramos durante la época prehispánica tardía y, de esta manera, vislumbrar la morfología de la red vial en dicha época. Una recurrió a una modelización de flujos de movimiento sobre el palimpsesto vial, entre los asentamientos prehispánicos. La otra consistió en

\section{Suma en $\mathrm{km}$}

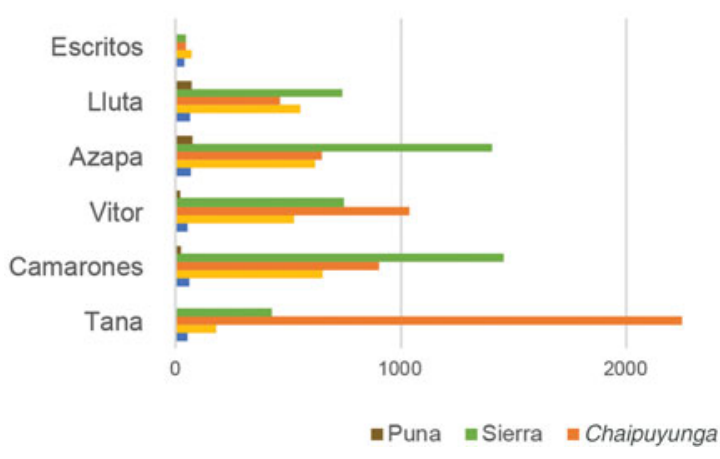

Densidad en $\mathrm{km} / \mathrm{km}^{2}$

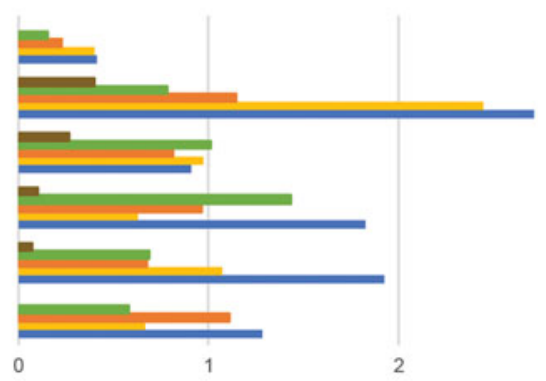

Figura 2. Distribución del palimpsesto vial por cuenca y piso. (Color en la versión electrónica) 
emplear un diagnóstico cronológico realizado a partir de una prospección pedestre en terreno, para evaluar la pertinencia de esta modelización de flujos.

Evaluación cronológica según aproximación topológica. Para la evaluación cronológica del palimpsesto, se desarrolló un modelo topológico de flujos entre asentamientos, con la finalidad de derivar probabilidades de uso contemporáneo de los tramos basado en el diagnóstico cronológico de los asentamientos. Esta modelización se fundamenta en el postulado que cuanto mayor sea la cantidad de flujo teórico que circula (entre asentamientos) por un determinado tramo, mayor es la probabilidad de que éste haya sido usado de forma contemporánea a estos asentamientos. Los flujos fueron modelizados sobre el palimpsesto vial a partir del cálculo de los itinerarios más cortos entre sitios contemporáneos, empleando la herramienta closest facility de ArcGis 10.7, basados en el largo de las polilíneas.

Se evaluaron distintos costes derivados de la pendiente para ajustar la distancia a una función de caminata pedestre (Nuninger et al. 2020), pero se descartó su aplicación en esta aproximacion inicial porque su implementación implicaría criterios de modelización más elaborados (relativos a una diversidad de agentes, funciones y modos de movilidad). Por este motivo, se seleccionó a la distancia más corta como la variable más genérica y robusta para esta modelización. Cabe notar que, junto con la impedancia de distancia, el efecto borde constituye otro condicionante de la modelización, lo que debe tomarse en cuenta al interpretar los resultados.

Diagnóstico cronológico según prospección pedestre. Fueron inspeccionados en terreno, $157 \mathrm{~km}$ de caminos en las cuencas de Lluta y Azapa, los cuales corresponden a 203 tramos del palimpsesto vial. Se realizó una prospección pedestre intensiva de estos tramos para relevar información directa sobre la arquitectura vial, los artefactos dispersos a lo largo de los caminos, y los sitios asociados (Mendez-Quiros 2020). Se registraron 474 puntos con evidencias materiales asociadas a las vías, distribuidas en 127 tramos. La industria lítica, el arte rupestre, los artefactos de hierro, los fragmentos de vidrio y cerámica, además de los restos óseos de fauna (équidos y camélidos) permitieron diagnosticar usos prehispánico, colonial y republicano de los tramos.

De acuerdo con los estilos decorativos y patrones de pasta cerámica, se identificaron 154 registros prehispánicos tardíos, de los cuales 115 se asocian al PIT y 69 al HT. En suma, cerámica prehispánica tardía se identificó en 81 tramos (correspondientes a $109 \mathrm{~km}$ ); 79 de ellos asociados a cerámica PIT y 52 a cerámica de estilo incaico (Figura 3 ).

El diagnóstico cronológico por prospección pedestre respalda, en gran medida, la evaluación mediante modelización de flujos: 70 de los 81 tramos con evidencias prehispánicas tardías identificadas in situ integran la red vial modelizada por flujos entre asentamientos prehispánicos tardíos. Sin embargo, la ausencia de materiales in situ en 89 de los 162 tramos incluidos de la red prehispánica modelizada nos invita a tener cierta cautela con los resultados de la modelización, aunque también es cierto que la ausencia de evidencia material en un tramo no es argumento suficiente para descartar su uso en una determinada época.

\section{Resultados}

\section{Patrones de asentamiento}

El poblamiento prehispánico tardío en los valles de Arica se extendió desde la costa hasta las cabeceras de valle. El asentamiento habitacional más elevado se localiza a $3.550 \mathrm{~m} \mathrm{snm}$. El análisis de densidad del poblamiento, según la modelización de núcleos delimitados por isócronas de una hora (distancia máxima hacia el asentamiento más próximo), da cuenta de un patrón de asentamiento discontinuo. Estos núcleos se asocian a nichos productivos con concentración de recursos, en los distintos pisos y cuencas, donde el agua es el factor determinante en esta región desértica. Existe una clara relación entre los caudales disponibles y el tamaño (y densidad) de los núcleos de poblamiento: tanto los caudales de los valles como la ocupación humana disminuyen progresivamente hacia el sur.

Los 129 asentamientos registrados se agrupan en 21 núcleos de poblamiento. En el valle de Lluta un extenso núcleo compuesto por 33 asentamientos entre el litoral y chaupiyunga (hasta 


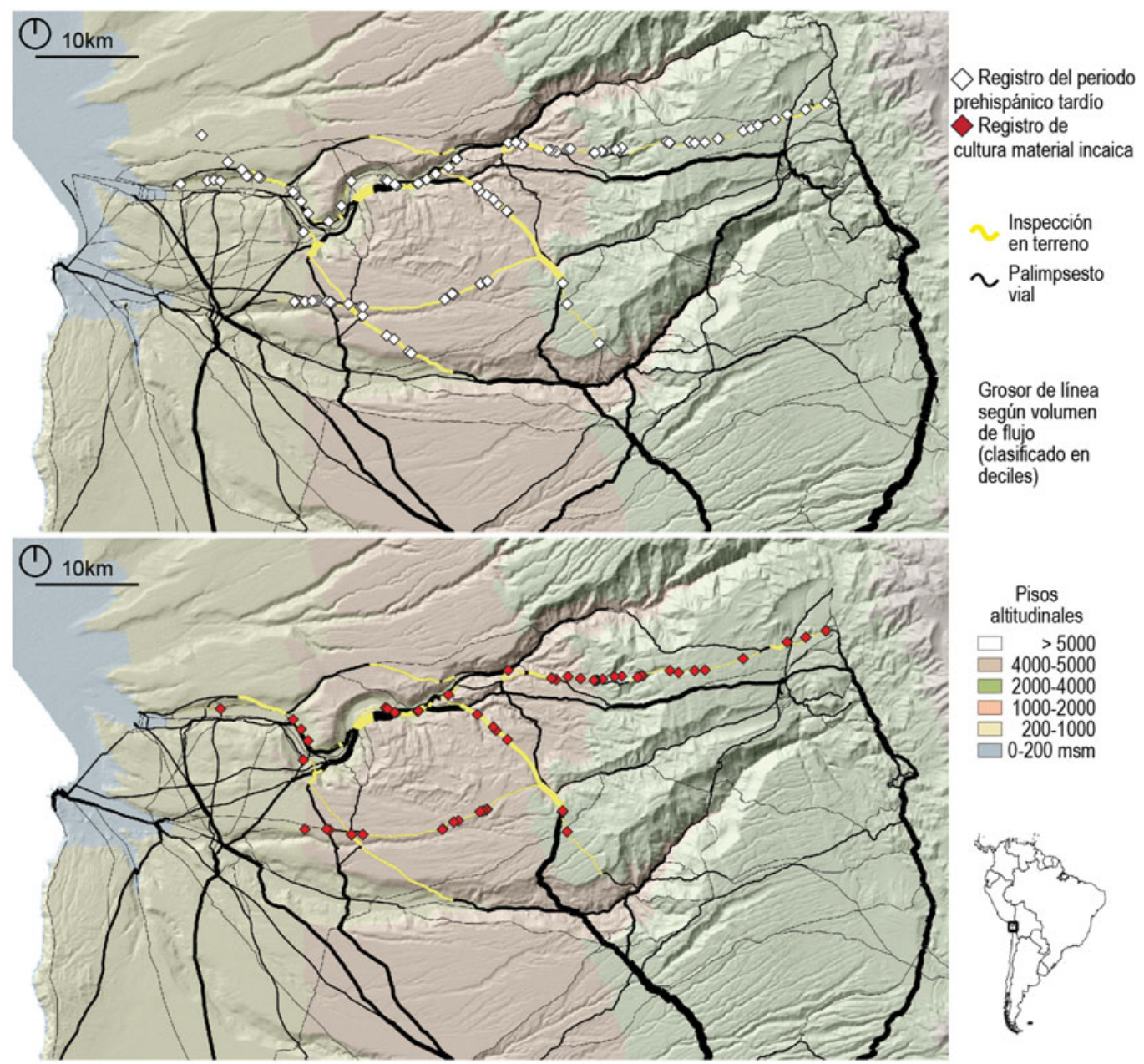

Figura 3. Diagnóstico cronológico de tramos del palimpsesto con resultados de prospección pedestre (tramos prospectados en amarillo). (Color en la versión electrónica)

$1.500 \mathrm{~m} \mathrm{snm}$ ) concentra el poblamiento de la cuenca. La cuenca de Azapa está segmentada en tres núcleos localizados en el litoral y valle bajo, en el chaupiyunga y en la sierra, siendo este último el segundo más numeroso de la región con 28 asentamientos entre 2.800 y $3.500 \mathrm{~m} \mathrm{snm}$. En Vitor y Camarones, el poblamiento es discontinuo, con núcleos pequeños y sitios dispersos en nichos acotados, alrededor de un gran núcleo que agrupa 18 asentamientos entre 1.500 y $3.200 \mathrm{~m}$ snm (Muñoz y Briones 1996). En Tana, la ocupación es escasa y escalonada, con dos núcleos pequeños (litoral y sierra) $\mathrm{y}$ dos sitios intermedios aislados.

En el litoral, las ocupaciones se concentran en torno a las desembocaduras y fuentes de agua dulce. Lluta y Camarones exhiben vestigios de un poblamiento litoral denso, mientras que la urbanización en Azapa esconde una densidad equivalente o incluso mayor. Es escasa la información sobre los asentamientos habitacionales del litoral: en Lluta, se documentaron viviendas cuadrangulares con muros de material ligero, y en Pisagua estructuras cuadrangulares, con bases de piedra y muros ligeros. Numerosos conchales evidencian la intensidad de la ocupación costera, mientras que la presencia de extensos cementerios sobre las terrazas litorales evidencia su valor simbólico.

En los valles bajos, la distribución del poblamiento se relaciona con el potencial agrícola. Lluta concentra la mayor densidad de sitios. 
Los asentamientos habitacionales se localizan a menudo sobre terrazas altas o sobre las laderas del valle, encima de los espacios agrícolas. La organización espacial y el grado de aglutinamiento de las estructuras son variables. La arquitectura doméstica predominante en Lluta y Azapa consiste en estructuras de material ligero y planta rectangular construidas sobre aterrazamientos. Camarones se distingue por el uso frecuente de piedras para reforzar las bases de las estructuras.

Los valles encajonados de chaupiyunga forman un polo de poblamiento generalmente denso. Los asentamientos se localizan principalmente sobre terrazas fluviales y conos de deyección inactivos. Existen poblados en excelente estado de conservación en Lluta, Azapa y Camarones. La arquitectura doméstica emplea muros de piedra y plantas circulares y cuadrangulares, con excepción de la cuenca de Tana donde las viviendas comparten el patrón descrito para los valles bajos.

La sierra es el piso con la mayor cantidad de asentamientos. En este escenario fisiográfico escarpado, las cumbres y laderas de cerros son frecuentemente ocupadas. La cuenca alta de Azapa constituyó un notable polo de poblamiento asociado a extensos acondicionamientos agrícolas. El poblamiento de Vitor y Camarones se distingue por una menor densidad, mayor dispersión, y menor tamaño de los asentamientos. La sierra alberga los sitios arqueológicos más monumentales y mejor conservados, con asentamientos compuestos por hasta trescientas viviendas de piedra de forma circular.

La Figura 4 muestra la estructuración altitudinal del poblamiento, evidenciando perfiles verticales diferenciados por cuenca. En suma, el 75\% del poblamiento de la región se localiza en los pisos de sierra y valles bajos, concentrándose casi la mitad en el valle bajo de Lluta y la sierra de Azapa.

La estructuración de los núcleos de poblamiento deja en evidencia la organización territorial regional sobre la base de cuatro núcleos principales (91 asentamientos), combinado con tres núcleos secundarios (17 asentamientos) y 14 satélites relacionados a la explotación de nichos discretos. Este ordenamiento espacial es determinante para las interacciones, destacándose espacios centralizadores del poblamiento y los movimientos.

La materialidad imperial se evidencia por cerámica incaica en 62 sitios distribuidos en toda la región, con excepción de la cuenca de Tana. La distribución de los asentamientos locales con cerámica incaica análoga al patrón de asentamiento regional evidencia que la esfera incaica penetró la red de interacción regional en su conjunto. En cambio, arquitectura de estilo incaico se encuentra, de forma intrusiva, en tan sólo 13 asentamientos. Además de los tambos de Zapahuira (Az-40 y Az-124) y Taruguire, la arquitectura imperial más emblemática corresponde a los ushnu de Saguara y Pubriza (Az-59) (se sugiere otro en Molle Pampa Este [Llu-12]), a las kallankas de Pubrisa y Huaihuarani-Incahullo, además del sunturwasi de Incahullo, todos localizados en las tierras altas (Tabla 1).

\section{Redes viales e imperialismo}

Morfología de las redes viales prehispánicas. Para analizar la estructuración y volumen de flujos entre asentamientos, se modelizaron cuatro redes viales regionales sincrónicas (Figura 5): (1) la red local, entre asentamientos con arquitectura y cerámica local; (2) la red de la hegemonía incaica, entre asentamientos (locales) con cerámica incaica (intrusiva); (3) la red imperial, entre asentamientos con arquitectura incaica; y (4) la red hegemónica imperial, desde asentamientos con cerámica incaica hacia aquellos con arquitectura incaica. Se desarrolló un modelo de interacción genérico, que no contempla factores sociales complejos (de orden político y/o étnico) y otorga una agencia y peso equivalente a todos los sitios.

El volumen de flujos entre asentamientos evidencia y jerarquiza los ejes de circulación regional. En la red local, destacan los caminos longitudinales que articulan los principales núcleos de poblamiento: a través de la sierra de Lluta y Alto Azapa; a través de chaupiyunga de Lluta y Azapa y la sierra de Codpa y Camarones; el que asciende desde el valle bajo de Lluta hasta la sierra de Codpa-Camarones; y a través de los valles bajos de Lluta, Azapa y Vitor. Por otra parte, los ejes de circulación transversales, siguiendo la gradiente altitudinal, alcanzan una menor envergadura relativa, destacando el 


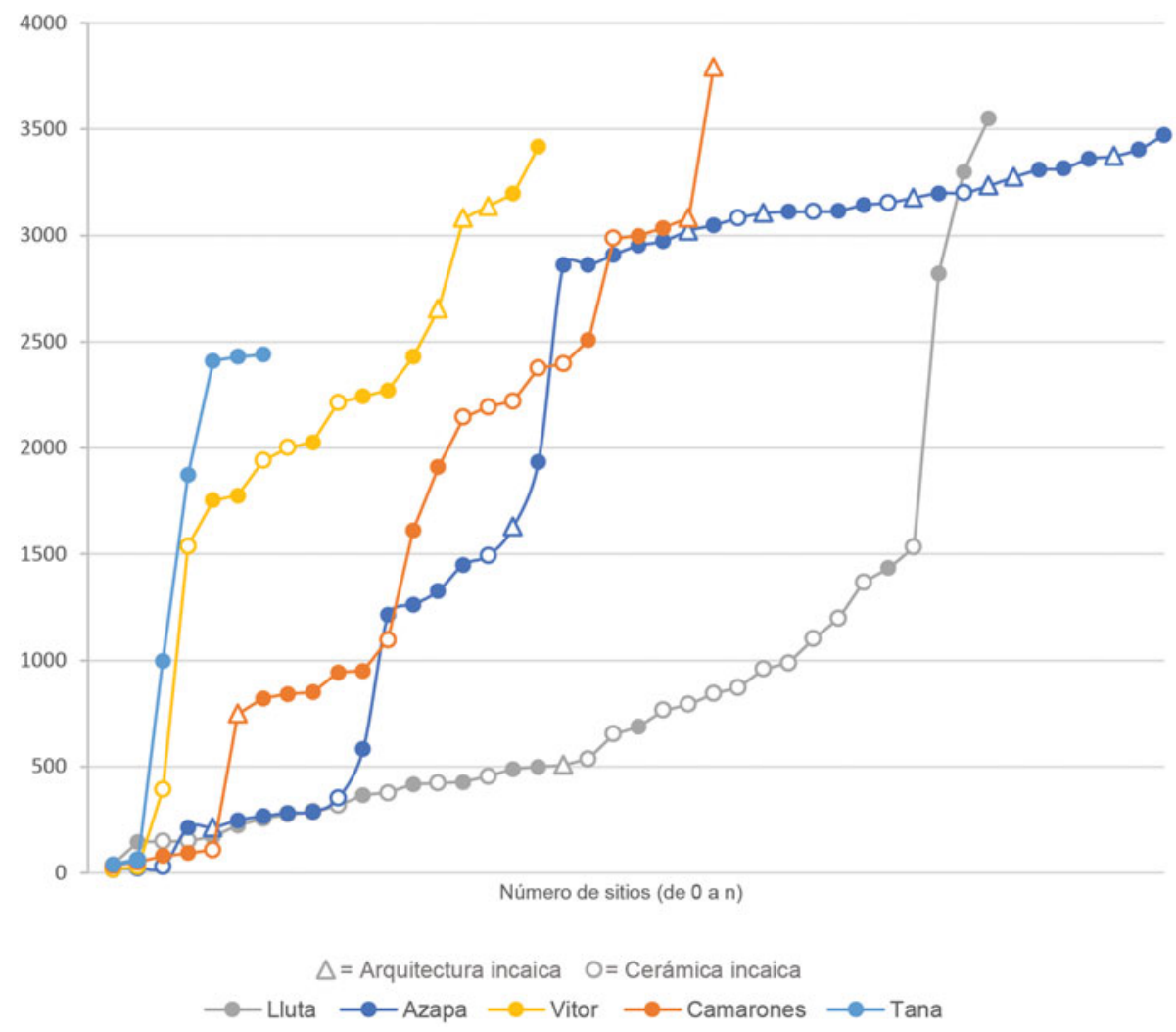

Figura 4. Distribución altitudinal de los sitios prehispánicos tardíos por cuenca. (Color en la versión electrónica)

camino que circula por Lluta y asciende hasta Alto Azapa, así como el de Azapa que recorre el chaupiyunga y asciende hasta la sierra. Dichos ejes principales están integrados a una red compleja y graduada, y coinciden parcialmente con una evaluación previa realizada a partir de criterios cualitativos (Mendez-Quiros y García 2018).

Las Figuras 5 y 6 dan cuentan de la morfología y características locacionales de las redes viales. La red local acumula unos $5.000 \mathrm{~km}$ de caminos, correspondiente a un $37 \%$ de los tramos del palimpsesto vial; si bien la sierra acumula la mayor cantidad de tramos, la mayor densidad se concentra en el litoral y valles bajos. La red de la hegemonía incaica incluye, a su vez, un $69 \%$ de los tramos de la red local, con patrones distribucionales comparables a ésta, diferenciándose por su reducido alcance al sur del río Camarones. La red imperial, por su parte, incluye un $44 \%$ de los tramos de la red vial de la hegemonía incaica. A diferencia de las anteriores, la mayor cantidad y densidad de tramos se concentra en la sierra (donde se localiza el único eje principal), con excepción de Lluta, cuyo valle bajo alcanza la mayor densidad.

Sobre la base de las isócronas de una hora desde los asentamientos, se distingue un conjunto de caminos que participan en una movilidad local, y otro conjunto que participa en una movilidad internúcleos de poblamiento. A pesar de la mayor envergadura de estos últimos, ambos conjuntos suman una cantidad equivalente de caminos. En una lógica multiescalar, los tramos intranúcleos corresponden al inicio de itinerarios de alcance internúcleos.

Imperialismo y control del movimiento. Dos hipótesis fueron formuladas para contrastar el control imperial de la movilidad en la región. La primera plantea que los sitios con arquitectura incaica se localizarían en espacios estratégicos de la red vial, lo cual se evalúa mediante el análisis de centralidad y concentración de flujos, en los sitios. La segunda establece que el poder incaico se expresaría en el control de los ejes de 


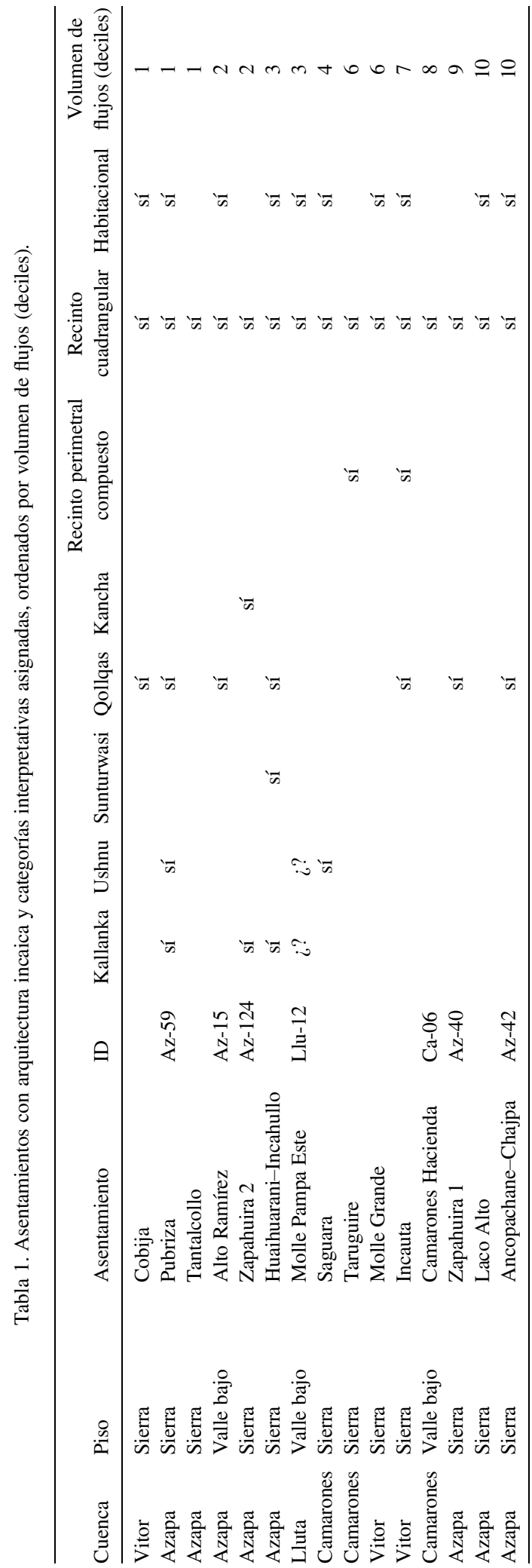

circulación. Ello se estudia mediante la comparación de la morfología y volumen de flujos entre las distintas redes viales, a partir de correlaciones y proporciones de flujos imperiales y locales, en los tramos.

La intermediación resultó el indicador de centralidad más explícito de las propiedades topológicas de los sitios incaicos. Ella es relativa a la acumulación de flujos de los itinerarios más cortos entre todos los sitios (Figura 5). Asimismo, este índice distingue los sitios con mayor potencial de mediar los flujos de movimiento en la región, lo cual puede interpretarse en términos de influencia (sobre) y/o control de la circulación en la red (Jenkins 2001). En nuestro caso, los 15 sitios con arquitectura incaica tienen un índice promedio de intermediación normalizada dos veces superior al índice promedio de los otros 114 sitios.

La centralidad de proximidad, la cual es comúnmente analizada para describir la accesibilidad de los sitios al conjunto de la red e interpretada como indicador de posición territorial estratégica (Zori y Brant 2017), no resulta interpretable aquí, a nivel de sitio, debido a la distribución de los asentamientos en núcleos dispersos, además de la alta resolución del registro asociada a la envergadura del área de estudio. Asimismo, la centralidad de proximidad refiere aquí a la situación topológica de los núcleos de poblamiento, coincidiendo la ubicación central en el área de estudio con un índice más elevado: específicamente los sitios del chaupiyunga de Azapa y Codpa.

La concentración de flujos evidencia también cierta preponderancia de los sitios con arquitectura incaica, los cuales concentran en promedio 1,3 veces más flujos que los otros sitios. Esta medida básica corresponde a la suma de los flujos acumulados por los tramos conectados a cada sitio. Siete de los sitios con arquitectura incaica se sitúan en los primeros tres deciles de la clasificación de este índice (Tabla 1).

Se realizaron dos pruebas estadísticas centradas en los caminos a partir de los valores topológicos de los tramos. Primero, se calculó la correlación entre los volúmenes de flujo de los tramos para evaluar la semejanza morfológica entre las redes viales. El índice de correlación positivo $(0,65)$ entre los volúmenes de flujo 

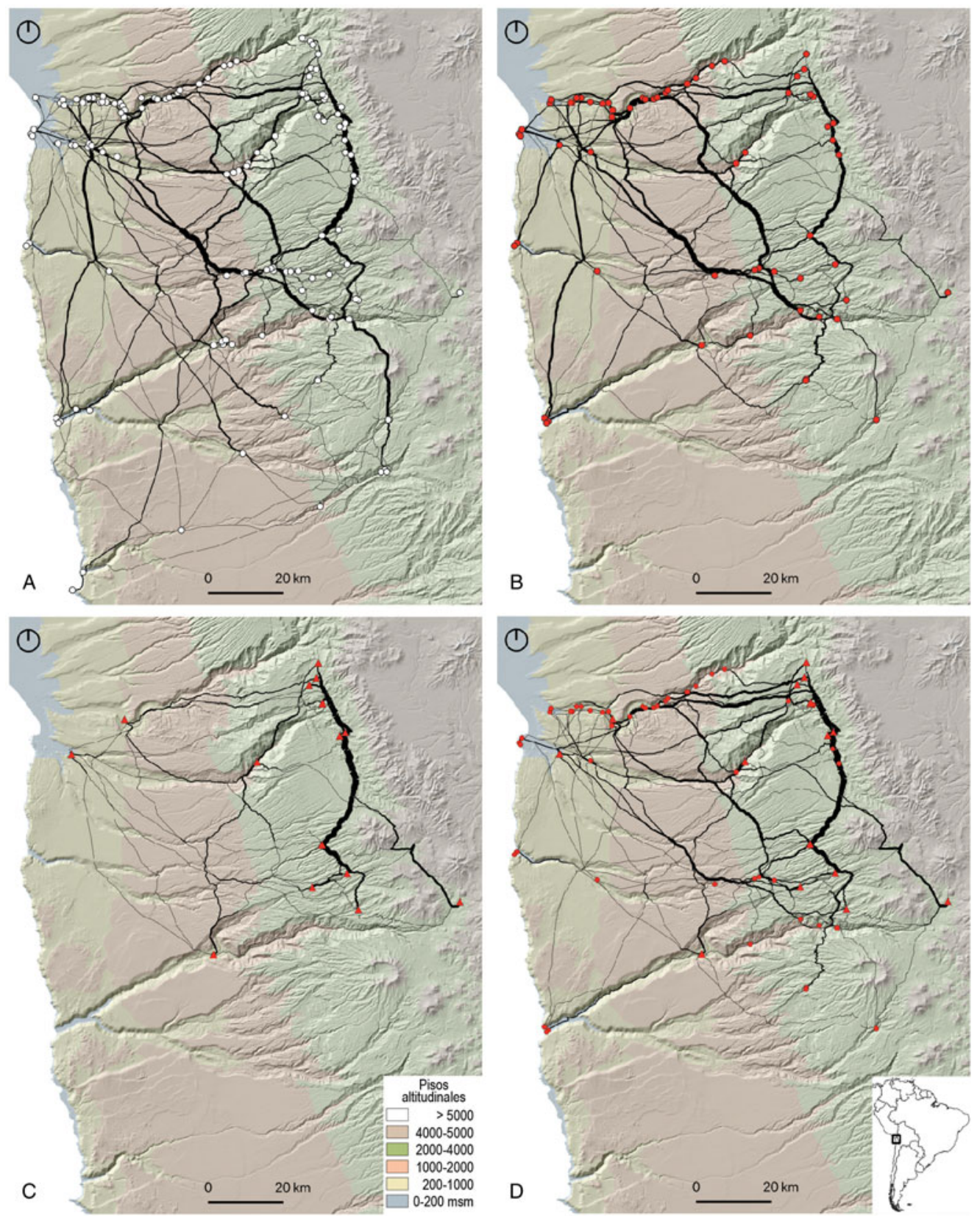

\begin{tabular}{lllll}
\hline Red vial & & $\mathrm{N}$ sitios & Suma $\mathrm{km}$ & Densidad km/ $\mathrm{km}^{2}$ \\
\hline A. Local & $\bigcirc-\bigcirc$ & 129 & 4924 & 0,31 \\
B. Hegemonia incaica & $\bigcirc-\bigcirc$ & 67 & 3456 & 0,27 \\
C. Imperial & $\Delta-\Delta$ & 15 & 1450 & 0,12 \\
D. Hegemonia imperial & $\bigcirc \rightarrow \Delta$ & 67 & 2973 & 0,23 \\
\hline
\end{tabular}

$$
\text { Grosor de línea según volumen de flujo (clasificado en deciles) }
$$

Figura 5. Modelización de redes viales prehispánicas tardías. (Color en la versión electrónica) 
Suma en km

A. Red vial local

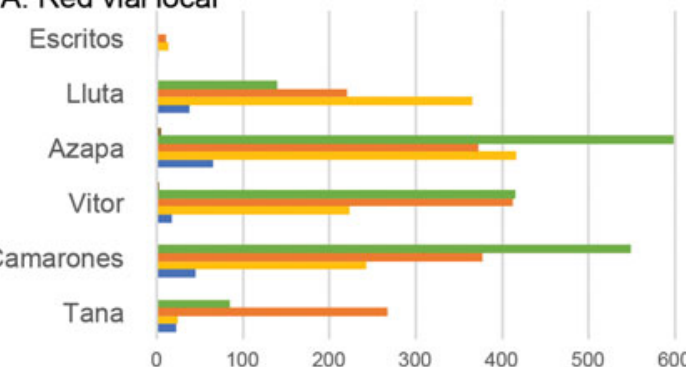

B. Red vial de la hegemonía cultural incaica

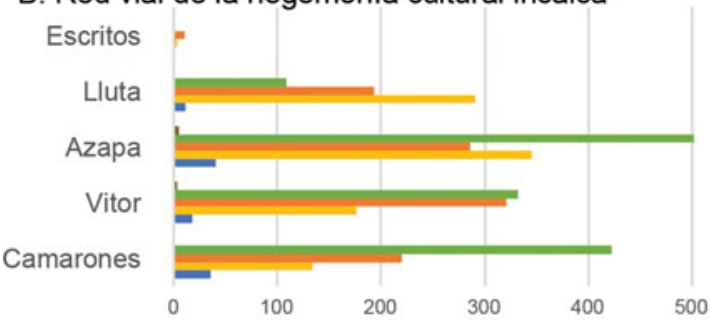

C. Red vial imperial

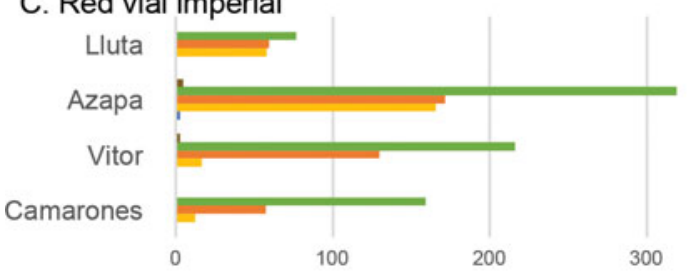

D. Red vial de la hegemonía imperial

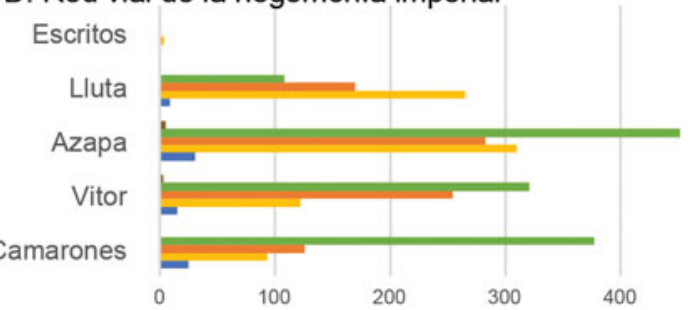

m Puna $=$ Sierra $=$ Chaipuyunga
Densidad en $\mathrm{km} / \mathrm{km}^{2}$
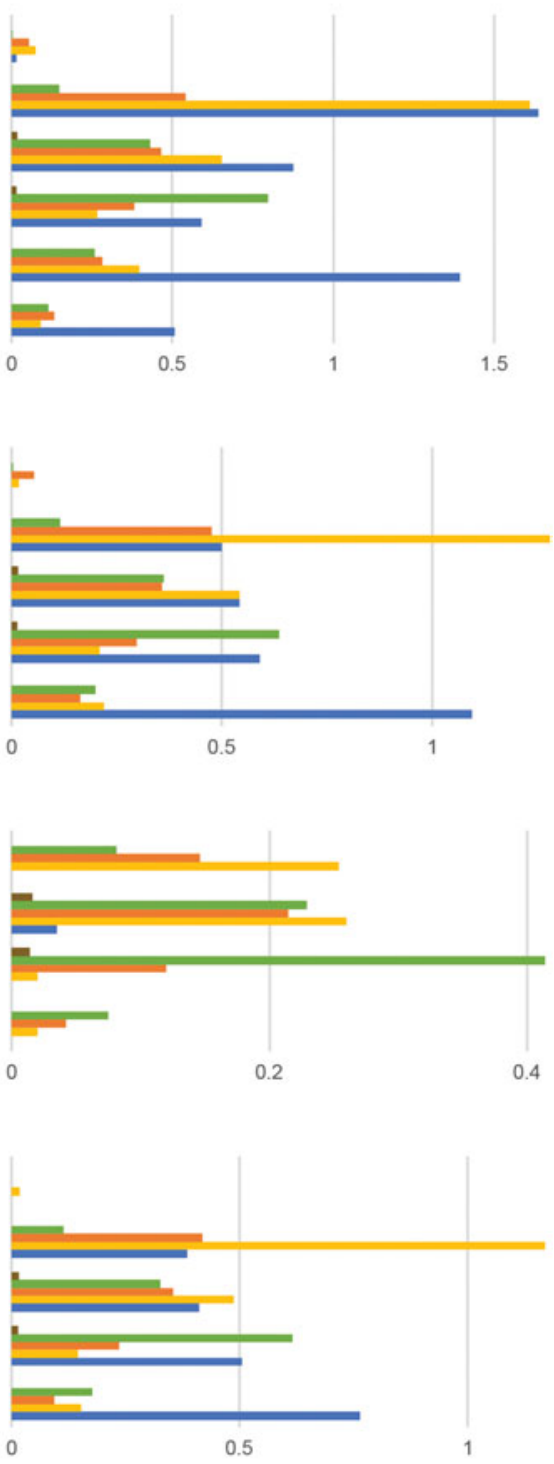

=Valle bajo =Litoral

Figura 6. Características locacionales, por cuenca y piso, de las redes viales prehispánicas tardías. (Color en la versión electrónica)

de las redes imperial y local evidencia cierto solape entre ambas. En este sentido, resulta especialmente llamativo que el índice mayor $(0,66)$ corresponda a la correlación entre la red imperial y la red de sitios sin evidencia material incaica.

Finalmente, la proporción de flujos entre la red imperial y el volumen total de flujos asociados a un tramo constituye una medida complementaria, para evaluar el potencial control imperial de los caminos. El volumen de flujos de la red imperial representa, en promedio, el $1,5 \%$ de los flujos de la red local, el 7\% de los flujos de la red de hegemonía incaica y el $3 \%$ de los flujos de la red entre sitios sin cultura material incaica. Esta medida de proporción permite 
ponderar los resultados de correlación entre las redes: por ejemplo, el hecho de que la proporción de flujos imperiales decrezca en función del volumen de la red local invita a matizar la hipótesis del mayor interés imperial por controlar los tramos con alto volumen de flujo.

Este conjunto de estadísticas cobra mayor sentido considerando las configuraciones locales en el área de estudio, especialmente por la estructuración del patrón de asentamiento en núcleos dispersos, la que implica dinámicas topológicas multiescalares. Además, cabe recordar la naturaleza parcial del registro arqueológico analizado, tomando en cuenta las especificidades locales relacionadas con la integridad y precisión del registro. Sin embargo, desde el punto de vista de la síntesis cuantitativa, los distintos indicadores, calculados a partir de las propiedades topológicas de sitios y caminos, coinciden en destacar cierto protagonismo de los sitios con arquitectura incaica en la estructuración de los flujos de movimiento en la región, a pesar de la distribución irregular de estos sitios en ella.

\section{Discusión}

\section{Imperialismo y movilidad}

El enfoque sobre redes viales ofrece una perspectiva sobre el imperialismo incaico alternativa a las narrativas basadas en la interpretación de sitios. Permite reflexionar sobre la negociación del poder imperial, no solamente desde los escenarios locales, sino también a través de las interacciones entre ellos, a escala regional. Esta perspectiva enfocada en el movimiento materializado por los caminos invita a considerar las implantaciones imperiales no solamente como centros de poder, sino también como nodos implicados en el control de flujos de bienes, ideas y personas, lo que resulta especialmente estratégico en el contexto de una organización socioterritorial basada en redes de asentamientos dispersos en nichos ecológicos diferenciados. Desde un punto de vista teórico, este enfoque atenúa el carácter dicotómico del modelo de control territorial/hegemónico, ya que el dominio de las redes viales permite controlar directamente quienes transitaban por ellas, además de penetrar y mediar los flujos de información que circulaban en ellas. Por este motivo, queda en evidencia que la red vial imperial no se limitaba a una o dos rutas exclusivas, sino que estaba formada por la estructura de las interacciones socioespaciales relativas al patrón de asentamiento regional.

Además de modelizar la morfología de la red imperial, los análisis de flujos entre implantaciones incaicas permiten evaluar la jerarquización entre sus ejes. La hipótesis tradicional respecto de dos ejes paralelos recorriendo la sierra y los llanos resulta confirmada sólo parcialmente por la modelización: mientras que el protagonismo del eje serrano está confirmado por los flujos teóricos, el eje de los llanos resulta difuso, especialmente en la red entre asentamientos con arquitectura incaica (Figura 5). En cambio, la modelización evidencia ejes importantes que no han sido reconocido hasta ahora. El segundo eje de mayor acumulación de flujos corresponde a un eje transversal que conecta al valle de Lluta con el piso serrano. Su prospección pedestre integral (entre Mollepampa y Zapahuira) evidenció su uso durante el Horizonte Tardío (MendezQuiros 2020), no obstante éste había sido previamente asociado a la época colonial (Choque y Muñoz 2016). Finalmente, la modelización de flujos evidencia varios ejes intercuencas conectando núcleos del chaupiyunga y valles bajos, cuya materialidad tendrá que ser evaluada mediante futuras inspecciones en terreno.

Entendemos que todos los sitios con arquitectura incaica están conectados a la red vial imperial. Considerando sus características materiales y su relación con el poblamiento local, estos pueden ser agrupados bajo tres categorías: implantaciones imperiales en poblados de raigambre local; colonias relacionadas con la economía política imperial; y sitios no habitacionales con función logística y ceremonial. Su asociación con distintos volúmenes de flujos es indicativa de las relaciones sostenidas al interior del sistema de interacciones. Por ejemplo, destaca la estación vial de Zapahuira por ser el asentamiento imperial más relacionado con la estructura regional de interacciones, gracias a su ubicación estratégica en la encrucijada de dos ejes acumulando significativos volúmenes de flujos tanto en las redes incaicas como en la red local, además de su emplazamiento en una zona con reducido poblamiento local. 


\section{Arqueología del Qhapaq Nan}

Si bien varios estudios han evidenciado la complejidad y diversidad de las infraestructuras y huellas de movilidad en los Andes (Hyslop 1991; Nielsen 2017), la mayoría de las investigaciones sobre caminos incaicos se han centrado en la planificación y singularidad de una infraestructura monumental que materializa el poder imperial, generando asimetrías en los territorios atravesados por el camino principal (Arkush 2017; Wilkinson 2019). El carácter planificado del sistema vial imperial, heredado de los relatos etnohistóricos (p.e., Cieza de León 2005 [1553]) $\mathrm{y}$ generalmente asumido por las teorías neo-evolucionistas sobre complejidad social (Earle 1991, 2009), constituyó también la hipótesis de trabajo de las aproximaciones topológicas buscando evidenciar la racionalidad espacial del dominio incaico: por ejemplo, si "la distribución de los centros administrativos incaicos se explica más por factores globales relacionados con una estrategia de cobertura y vigilancia de la red imperial en su conjunto, que por factores locales relacionados con su articulación con el poblamiento local" (Wernke et al. 2017:126, adaptado de Jenkins 2001).

Sin dejar de lado el papel territorial de los tramos monumentales resultantes de acondicionamientos planificados por el imperio, aquí hemos buscado aprehender el sistema vial incaico desde un enfoque más amplio, considerando una mayor ubicuidad relativa a su relación con las redes viales locales. Esta iniciativa resultó efectiva al evidenciar como parte del sistema vial imperial ejes viales no identificados previamente, como el eje transversal de Lluta (cuya materialidad incaica resultó comprobada por prospecciones pedestres). La modelización de flujos, considerando el patrón de asentamiento regional en su conjunto, permitió también distinguir entre sitios y caminos heredados de las redes de interacciones locales y otros más probablemente producto de una planificación imperial, como lo sugerimos para el caso del tambo de Zapahuira.

Por cierto, el presente trabajo sugiere que la arqueología del sistema vial incaico ganaría en ampliar el foco al considerar conjuntos de caminos conectados en lugar de tramos específicos, principalmente por dos razones. Primero, porque las redes viales están estructuradas por dinámicas multiescalares que implican distintas jerarquías de caminos, distintos sistemas de movilidad e incluso una pluralidad de itinerarios por una misma ruta, de acuerdo con actores y propósitos del movimiento diversos. Segundo, porque los caminos son una infraestructura territorial con un alto potencial de resiliencia a través del tiempo, es decir que la conservación de su impronta predispone a su reutilización, formal o marginal, tras fases de reconfiguración de los patrones de asentamientos e incluso de los sistemas de movilidad (Nuninger et al. 2020; Robert y Verdier 2014).

Finalmente, es necesario resaltar el carácter experimental del presente trabajo, el cual es perfectible tanto a nivel de registro y análisis del palimpsesto vial, como de modelización cronológica de las redes viales. En primer lugar, a pesar de las óptimas condiciones de preservación en los valles de Arica, el registro base de caminos es incompleto, debido a procesos erosivos que generan desconexiones de ciertos sitios y caminos, condicionando ciertas imprecisiones en los itinerarios modelizados. En segundo lugar, aunque recurrentemente empleada en análisis de redes espaciales, es cuestionable la modelización de redes según el postulado del itinerario más corto: una modelización más sofisticada compararía distintos costes y variables, de acuerdo con distintos hipotéticos sistemas de movilidad y actores (Barthélemy 2018; Verhagen et al. 2019). Finalmente, nuestro estudio no escapa al viejo problema que constituye el diagnóstico cronológico de caminos en arqueología. Si bien hemos demostrado la congruencia entre resultados de modelización de flujos y datos empíricos de terreno, los resultados de la modelización tienen que considerarse con cautela, en calidad de pistas de investigación, hasta completar la prospección pedestre de los $13.000 \mathrm{~km}$ de caminos.

\section{Conclusión}

La síntesis sobre patrones de asentamiento y redes viales en los valles de Arica que hemos desarrollado constituye una actualización conceptual y metodológica del trabajo pionero de Muñoz y Briones (1996). La documentación aérea de alta resolución y herramientas geomáticas, han 
permitido consolidar y detallar significativamente el registro. Asimismo, una base de datos de 160 sitios arqueológicos de la época prehispánica tardía y el registro de un palimpsesto vial de $13.000 \mathrm{~km}$ han sido empleados para investigar el patrón de asentamiento y las redes viales durante la coyuntura histórica incaica.

En línea con el planteamiento de Smith (2005:832), que "los antiguos estados se comprenden mejor mediante modelos de redes que de territorios delimitados" [traducción nuestra], se empleó el registro de sitios y caminos para investigar la relación entre la configuración de las redes viales y el imperialismo incaico. A su vez, siguiendo la propuesta de Wernke (et al. 2017:125) que "el espacio del Tawantinsuyu no se concebía como una sola red, sino como una serie de redes superpuestas con distintos fines, significancias y funciones", se modelizaron distintas redes de interacciones entre asentamientos, a través del palimpsesto vial, para evaluar intersecciones entre las redes incaicas y locales.

Los primeros resultados del presente análisis del imperialismo en los valles de Arica, desde la perspectiva de las interacciones materializadas por los caminos, deja en evidencia el despliegue de una ingeniería socioespacial del movimiento compleja. Aparentemente, esta fue desarrollada mediante una mezcla de planificación de infraestructuras imperiales con una hábil adaptación a la configuración vial y demográfica local, cuyas evidencias son visibles más bien a través de múltiples arreglos de las dinámicas locales que de una cuantiosa inversión estatal para un ordenamiento territorial regional planificado desde arriba.

Agradecimientos. Aportaron financiamientos ANID BecasChile, CONICYT/PIA Anillo SOC1405 y el Ministerio de Europa y relaciones exteriores de Francia: proyectos Altos Arica y Redes Andinas. Además, este proyecto ha recibido financiación del programa de investigación e innovación Horizon 2020 de la Unión Europea según el convenio de subvención Marie Skłodowska-Curie N ${ }^{\circ} 800617$ RoadNet_Andes. Alvaro Romero, Rolando Ajata y Calogero Santoro contribuyeron a la compilación de la base de datos. El Laboratorio de Arqueología Cuantitativa/UAB y Joan Nunes facilitaron infraestructuras y asesoramiento técnico. La prospección de caminos fue autorizada por el Consejo de Monumentos Nacionales (Ord 564/2018) y llevada a cabo gracias a la colaboración de Magdalena García, Rubén Santos y Denny Isler.
Declaración de disponibilidad de datos. El juego de datos (sitios y caminos) está disponible en el repositorio público Digital.CSiC, accesible en la siguiente URL: http://hdl.han dle.net/10261/217541.

Material suplementario. Para acceder al material suplementario que acompaña este artículo, visitar https://doi:10.1017/ laq.2020.100.

Tabla Suplementaria 1. Sitios arqueológicos correspondientes a asentamientos y cementerios del periodo prehispánico tardío en los valles de Arica.

\section{Referencias citadas}

Ajata, Rolando

2015 Patrones de asentamiento prehispánico en el valle de Codpa, Norte de Chile (1.000-1.400 d.C.): Una propuesta de articulación territorial de los asentamientos. Tesis pregrado, Departamento de Antropología, Universidad de Chile, Santiago.

Álvarez, Luis

1991 Etnopercepciones andinas: Valles dulces y salados en la vertiente occidental de los Andes. Diálogo Andino 10:9-19.

Arkush, Elizabeth

2017 Caminos hacia el futuro: Nuevas tendencias en el estudio de caminos y rutas. En Nuevas tendencias en el estudio de los caminos, editado por Sofia Chacaltana, Elizabeth Arkush y Giancarlo Marcone, pp. 444 465. Ministerio de Cultura, Proyecto Qhapaq Nan, Lima.

Bailey, Geoff

2007 Time Perspectives, Palimpsests and the Archaeology of Time. Journal of Anthropological Archaeology 26:198-223.

Barthélemy, Marc

2018 Morphogenesis of Spatial Networks. Lecture Notes in Morphogenesis 14. Springer, Cham, Suiza.

Chacaltana, Sofia, Elizabeth Arkush y Giancarlo Marcone (editores)

2017 Nuevas tendencias en el estudio de los caminos. Ministerio de Cultura, Proyecto Qhapaq Nan, Lima.

Choque, Carlos

2009 El Colesuyu meridional: Espacio de articulación económica y cultural hispano-indígena en la segunda mitad del siglo XVI. Allpanchis Phuturinka 73/ 74:241-267.

Choque, Carlos e Iván Muñoz

2016 El camino real de la plata: Circulación de mercancías e interacciones culturales en los valles y Altos de Arica (siglos XVI al XVIII). Historia 49(1):57-86.

Cieza de León, Pedro

2005 [1553] Crónica del Perú: El señorío de los Incas. Editado por Franklin Pease. Biblioteca Ayacucho, Caracas, Venezuela.

Covey, Alan

2000 Inka Administration of the Far South Coast of Peru. Latin American Antiquity 11:119-138.

D'Altroy, Terence

1992 Provincial Power in the Inka Empire. Smithsonian Institution, Washington, DC.

Dauelsberg, Percy

1959a Contribución a la arqueología del valle de Azapa. Boletín del Museo Regional de Arica 3:36-52. 
1959b Reconocimiento arqueológico del valle de Camarones: Cuya-Taltape. Boletín del Museo Regional de Arica 3:53-68.

1960 Reconocimiento arqueológico de los valles de Lluta, Vitor y la zona costera de Arica. Boletín del Museo Regional de Arica 4:70-77.

1983 Investigaciones arqueológicas en la sierra de Arica, sector Belén. Chungara 11:63-83.

Durston, Alan y Jorge Hidalgo

1997 La presencia andina en los valles de Arica, siglos XVI-XVIII: Casos de regeneración colonial de estructuras archipielágicas. Chungara 29:249-273.

Earle, Timothy K.

1991 Paths and Roads in Evolutionary Perspective. En Ancient Road Networks and Settlement Hierarchies in the New World, editado por Charles Trombold, pp. 10-16. Cambridge University Press, Cambridge.

2009 Routes through the Landscape: A Comparative Approach. En Landscapes of Movement: Trails, Paths, and Roads in Anthropological Perspective, editado por James E. Snead, Clark L. Erickson y J. Andrew Darling, pp. 253-269. University of Pennsylvania Museum of Archaeology and Anthropology, Philadelphia.

Flewett, Samuel, Thibault Saintenoy, Marcela Sepúlveda, Edward Fabian Mosso, Carolina Robles, Katherine Vega, Sebastian Guttierez, Álvaro Romero, Lydia Finney, Evan Maxey y Stefan Vogt

2016 Micro X-ray Flurorescence Study of Late PreHispanic Ceramics from the Western Slopes of the South Central Andes Region in the Arica and Parinacota Region, Chile: A New Methodological Approach. Applied Spectroscopy 70:1759-1769.

Hidalgo, Jorge

2004 Historia andina de Chile. Editorial Universitaria, Santiago de Chile.

Hidalgo, Jorge y Guillermo Focacci

1986 Multietnicidad en Arica, S. XVI: Evidencias etnohistóricas y arqueológicas. Chungara 16/17:137147.

Horta, Helena

2015 El señorío Arica y los reinos altiplánicos (1000-1540 d.C.): Complementariedad ecológica y multietnicidad durante los siglos pre-conquista en el norte de Chile. QILLQA Ediciones IAA, Universidad Católica del Norte, Antofagasta, Chile.

Hyslop, John

1984 The Inka Road System. Academic Press, Orlando, Florida.

1991 Observations about Research on Prehistoric Roads in South America. En Ancient Road Networks and Settlement Hierarchies in the New World, editado por Charles Trombold, pp. 28-33. Cambridge University Press, Cambridge.

Jenkins, David

2001 A Network Analysis of Inka Roads, Administrative Centers, and Storage Facilities. Ethnohistory 48:665-687.

Llagostera, Agustín

1976 Hipótesis sobre la expansión incaica en la vertiente occidental de los Andes Meridionales. En Homenaje al Dr. Gustavo Le Paige, S. J., editado por Hans Niemeyer, pp. 203-218. Universidad del Norte, Antofagasta, Chile.

Lumbreras, Luis

1981 Arqueología de la América andina. Milla Batres, Lima.
Masuda, Shozo, Izumi Shimada y Craig Morris (editores)

1985 Andean Ecology and Civilization: An Interdisciplinary Perspective on Andean Ecological Complementarity. Papers from Wenner-Gren Foundation for Anthropological Research Symposium no. 91. University of Tokyo Press, Tokyo.

Mendez-Quiros, Pablo

2020 Redes viales y movilidad en los Valles Occidentales, Andes Centro Sur (siglos XIII-XVIII). En Un imperio, múltiples espacios: Perspectivas de los análisis espaciales en la arqueología inca, editado por Giancarlo Marcone, pp. 131-159. Proyecto Qhapaq Nan-Sede Nacional, Ministerio de Cultura del Perú, Lima.

Mendez-Quiros, Pablo y Magdalena García

2018 Territorialidad, flujos espaciales y modalidades de tránsito yuxtapuestas en la red vial de los Valles Occidentales (siglos X-XX). Revista Transporte y Territorio 18:40-69.

Mendez-Quiros, Pablo y Verónica Silva-Pinto (editores)

2015 Poblados maiceros y arquitectura funeraria en el valle de Lluta (1200-1600 dC). Consejo Nacional de la Cultura y las Artes, Iquique, Chile.

Morales, Mariano, Duncan A. Christie, Ricardo Villalba, Jaime Argollo, J. Pacajes, J. S. Silva, Claudio A. Alvarez, J. C. Llancabure y Claudia C. Soliz Gamboa

2012 Precipitation Changes in the South American Altiplano since 1300 AD Reconstructed by Tree-Rings. Climate of the Past 8:653-666.

Munizaga, Carlos

1957 Secuencias culturales de la zona de Arica. En Arqueología chilena: Contribuciones al estudio de la región comprendida entre Arica y La Serena, editado por Richard P. Schaedel, pp. 79-123. Centro de Estudios Antropológicos, Universidad de Chile, Santiago.

Muñoz, Iván

2018 El Qhapaq Ñan en los altos de Arica: Columna vertebral del poblamiento prehispánico tardío, Norte de Chile. Boletín del Museo Chileno de Arte Precolombino 22(2):115-132.

Muñoz, Iván y Luis Briones

1996 Poblados, rutas y arte rupestre precolombinos de Arica: Descripción y análisis de sistema de organización. Chungara 28:47-84.

Muñoz, Iván y Juan Chacama

2006 Complejidad social en las alturas de Arica: Territorio, etnicidad y vinculación con el Estado Inca. Ediciones Universidad de Tarapacá, Arica, Chile.

Muñoz, Iván y Mariela Santos

1998 Desde el período Tiwanaku al Indígena Colonial: Uso del espacio e interacción social en la Quebrada de Miñita, Norte de Chile. Diálogo Andino 17:69-114.

Murra, John

1975 El control vertical de un máximo de pisos ecológicos en la economía de las sociedades andinas. En El mundo andino: Población, medioambiente y economía, editado por John V. Murra, pp. 85-125. Instituto de Estudios Peruanos, Pontificia Universidad Católica del Perú, Lima.

Nielsen, Axel

2017 Actualidad y potencial de la arqueología internodal surandina. Estudios Atacameños 56:299-317.

Niemeyer, Hans y Virgilio Schiappacasse

1981 Aportes al conocimiento del período tardío del extremo norte de Chile: Análisis del sector Huancarane del valle de Camarones. Chungara 7:3-103.

1998 Patrones de asentamiento incaicos en el Norte Grande de Chile. En La frontera del Estado Inca, 
editado por Tom Dillehay y Patricia Netherly, pp. 3351. Fundación Alexander Von Humboldt, Editorial Abya Yala, Quito.

Niemeyer, Hans, Virgilio Schiappacasse e Iván Solimano

1971 Padrones de poblamiento en la Quebrada de Camarones (Provincia de Tarapacá): Estudio preliminar que comprende el sector medio y superior del valle. En Acta del VI Congreso de Arqueología Chilena, pp. 115-137. Universidad de Chile, Santiago.

Nuninger, Laure, Thibault Saintenoy, Philip Verhagen, Thérèse Libourel, Pablo Mendez-Quiros y Xavier Rodier

2020 Une archéologie du mouvement pour la compréhension des dynamiques de peuplement. En 5e colloque international Population, temps, territoires; Population, Time, Territories; Población, tiempo, territorios Proceedings 18-20 novembre 2020, Centre des colloques du campus Condorcet, Paris -Aubervilliers, pp. 220-225. Collège international des sciences territoriales (CIST) Fédération de recherche, Paris.

Oyaneder, Adrian y Camila Alday

2016 Catastro arqueológico del valle de Camarones: Cursos bajo y medio. Consejo Nacional de la Cultura y las Artes, Arica, Chile.

Raimondi, Antonio

1966 [1876] El Perú. Universidad Nacional de Ingeniería, Lima.

Robert, Sandrine y Nicolas Verdier

2014 Introduction générale. En Dynamique et résilience des réseaux routiers: Archéogéographes et archéologues en Île-de-France, editado por Sandrine Robert y Nicolas Verdier, pp. 7-10. Supplément à la Revue Archéologique du Centre de la France Series 52. FERACF, Tours, Francia.

Romero, Álvaro, Rolando Ajata y Manuel Méndez

2008 Registro sistemático de los yacimientos arqueológicos de Zapahuira y Copaquilla. En Patrimonio y comunidades indígenas aymara. Compilación de registro sistemático de yacimientos arqueológicos del sector de Zapahuira y Copaquilla, compilado por Leslia Véliz, pp. 11-67. Corporación Nacional de Desarrollo Indígena, Consultora Mallku, Arica.

Romero, Álvaro, Calogero Santoro y Mariela Santos

2000 Asentamientos y organización sociopolítica en los tramos bajo y medio del valle de Lluta. En III Congreso de Antropología Chilena, pp. 696-706. Temuco, Chile.

Rostworowski, María

1986 La región del Colesuyu. Chungara 16/17:127-135.

Saintenoy, Thibault, Rolando Ajata, Álvaro Romero y Marcela Sepúlveda

2017 Arqueología del territorio aldeano prehispánico tardío en los altos de Arica: Aportes de la fotointerpretación satelital para el estudio regional de la cuenca alta de Azapa. Estudios Atacameños 54:85-110.

Saintenoy, Thibault, Federico González y Mauricio Uribe

2019a Desde la perspectiva de la isla: La fábrica territorial incaica en la transecta andina del $18^{\circ} \mathrm{S}$ Arica-Carangas. Latin American Antiquity 30:393-414.

Saintenoy, Thibault, Antonio César González-García y Marta Crespo Fernandez

2019b The Making of an Imperial Agricultural Landscape in the Valley of Belén. Antiquity 93:1607-1624.
Santoro, Calogero

1983 Camino del Inca en la sierra de Arica. Chungara 10:47-56.

Santoro, Calogero, Sheila Dorsey Vinton y Karl J. Reinhard 2003 Inca Expansion and Parasitism in the Lluta Valley: Preliminary Data. Memorias do Instituto Oswaldo Cruz 98(S1):161-163.

Santoro, Calogero, Verónica Williams, Daniela Valenzuela, Álvaro Romero y Vivien Standen

2010 An Archaeological Perspective on the Inka Provincial Administration of the South-Central Andes. En Distant Provinces in the Inka Empire: Toward a Deeper Understanding of Inka Imperialism, editado por Michael Malpass y Sonia Alconini, pp. 44-74. University of Iowa Press, Iowa City.

Smith, Monica L.

2005 Networks, Territories, and the Cartography of Ancient States. Annals of the Association of American Geographers 95:832-849.

Strube-Erdmann, León

1963 Vialidad imperial de los Incas: Desde Colombia hasta Chile central y sur de Mendoza (Argentina) con inclusión de sus proyecciones orientales. Universidad Nacional de Córdoba, Córdoba, Argentina.

Verdier, Nicolas y Sandrine Robert

2009 La route en train de se faire ... Les Nouvelles de l'Archéologie 115:51-52.

Verhagen, Philip, Laure Groenhuijzen y Mark Nuninger

2019 Modelling of Pathways and Movement Networks in Archaeology: An Overview of Current Approaches. En Finding the Limits of the Limes: Modelling Demography. Economy and Transport on the Edge of the Roman Empire, editado por Philip Verhagen, Jamie Joyce y Mark Groenhuijzen, pp. 217-249. Springer, Cham, Suiza.

Von Hagen, Victor

1955 Highway of the Sun. Duell, Sloan and Pearce, New York.

Wernke, Steven, Gabriela Oré, Carla Menéndez, Hernández Garavito, Scotti Norman, Lauren Kohut, Lawrence Waller y Violetta Vylegzhanina

2017 Ejes de articulación: Análisis de la red espacial del Qhapaq Ñan en el sur del Perú. En Nuevas tendencias en el estudio de los caminos, editado por Sofia Chacaltana, Elizabeth Arkush y Giancarlo Marcone, pp. 125-143. Ministerio de Cultura, Proyecto Qhapaq Nan, Lima.

Wilkinson, Darryl

2019 Infrastructure and Inequality: An Archaeology of the Inka Road through the Amaybamba Cloud Forests. Journal of Social Archaeology 19:27-46.

Zori, Colleen y Erika Brant

2017 Lanzando una amplia red: Un análisis de redes sociales en los caminos incas en los valles costeros del norte de Chile. En Nuevas tendencias en el estudio de los caminos, editado por Sofia Chacaltana, Elizabeth Arkush y Giancarlo Marcone, pp. 73-99. Ministerio de Cultura, Proyecto Qhapaq Ñan, Lima.

Submitted June 1, 2020; Revised October 31, 2020; Accepted December 7, 2020 